\title{
Evaluating the Cleaning Procedures of Meat Slicers at Retail Delis in Metro Vancouver
}

\author{
Sasha Awan ${ }^{1}$, Helen Heacock ${ }^{2}$ \\ 1 Lead Author, B. Tech Student, School of Health Sciences, British Columbia Institute of Technology, 3700 Willingdon Ave. \\ Burnaby, BC V5G 3H2 \\ 2 Supervisor, School of Health Sciences, British Columbia Institute of Technology, 3700 Willingdon Ave. Burnaby, BC V5G 3H2
}

\begin{abstract}
Background: Ready-to-eat deli meats are widely consumed by the public; however they are also a high risk food for carrying Listeria monocytogenes. Listeriosis, an infection that can result from consumption of Listeria monocytogenes contaminated food, is the leading cause of deaths related to foodborne illness in Canada. Due to structural constraints and inadequate cleaning, mechanical slicers used to process deli meats have been implicated as a major source of Listeria monocytogenes contamination of deli meats. Several governing bodies, including local health authorities have published recommendations on the proper method of cleaning and sanitizing meat slicers to prevent the risk of contamination of deli meats. This study evaluated the compliancy of retail delis in Metro Vancouver to these recommendations and also assessed their knowledge of the risk associated with deli meats.

Methods: An in-person, self-administered paper survey was conducted at several retail delis and supermarkets. The survey questions determined the cleaning and sanitation procedures of meat slicers at the establishments and also assed knowledge of the risk associated with deli meats. Both nominal and numerical data was collected and analyzed using a Chi-squre test and a t-test.

Results: Based on the data collected, a statistically significant difference was identified between the cleaning procedures practiced by the establishments and those recommended to prevent pathogen transmission through meat slicers. The chi-square test revealed that there is a statistically significant association between the size of the establishment and the adequacy of cleaning procedures, with small-scale delis being less likely to comply with the cleaning practices that are recommended by governing bodies.

Conclusion: Cleaning procedures practiced at retail delis and supermarkets are not consistent with those recommended by regulatory agencies to prevent the transmission of pathogens such as Listeria monocytogenes from meat slicers to deli meats. Smaller retail delis are less likely to follow proper cleaning methods than larger supermarket delis. Educational intervention by health authorities may be needed to ensure that food establishments are informed of proper and timely cleaning procedures.
\end{abstract}

Key words: deli, meat slicers, cleaning and sanitation, Listeria monocytogenes

\section{Introduction}

Foodborne illness devastates the lives of millions of Canadians every year (1). Estimates suggest that the bacteria Listeria monocytogenes, the major human pathogen in the Listeria genus, is the leading cause of deaths related to foodborne illness, accounting for 33\% of known causes of foodborne deaths annually (1). Many outbreaks of Listeria monocytogenes infections have been linked to consumption of deli meats. Consequently, the Public Health Agency of Canada has designated deli meats as being high risk of carrying Listeria monocytogenes (2). This great risk of Listeria monocytogenes contamination of deli meat is a major concern for consumers because of the lack of a final kill step between processing and consumption of the product. While the elderly are among the largest consumers of deli meats, they are also a high risk group for contracting a serious form of listeriosis (2), an illness caused by the pathogenic listeria bacteria. Cross-contamination by Listeria monocytogenes during slicing of meat has been suspected as a mode of Listeria monocytogenes transmission to ready-to-eat meats (3).

The idea for this research was prompted after learning about the Maple Leaf Foods outbreak in 2008 in which 23 people died as a result of consuming prepackaged deli meats contaminated 
with Listeria monocytogenes (9). As an environmental health student, the author questioned if food safety precautions were being followed to mitigate the risk of Listeria monocytogenes contamination of ready-to-eat meats in small-scale facilities such as retail delis.

Research suggests that good slicer cleaning and sanitation practices can reduce the risk of foodborne illness caused by deli meats (2). Several agencies have published documents on how to properly clean and sanitize deli meat slicers to reduce the risk of foodborne illness. Furthermore, Vancouver Coastal Health Authority and Fraser Health Authority have published documents that list the steps needed to adequately clean and sanitize meat slicers to mitigate the risk of pathogen transmission from the slicer to the food being processed on it (3). The purpose of this study was to determine whether cleaning procedures recommended by health agencies are being followed in retail delis in Metro Vancouver.

\section{Evidence Review}

\section{Deli Meats}

Deli meats are a broad range of processed meats that are manufactured in the form of loaves or slices and sold in the deli section of grocery stores or at delicatessens (4). These include products such as sliced ham, salami, bologna, and other restructured meats. These meat products are fully cooked and ready to eat, requiring refrigeration for storage (4). Some of these products are pre-sliced and packaged for distribution to retail stores. Wholesale loaves however are commonly sold at food establishments and usually sliced using a retail slicer at the time of customer purchase (4). In Canada, the elderly are among the top consumers of deli meats along with school aged children (5).

\section{A high risk food}

Ready-to-eat deli meats are considered high risk for causing foodborne illness with Listeria monocytogenes being the pathogen most associated with the food. The Public Health Agency of Canada designates ready-to-eat deli meats as having a higher risk of carrying listeria
(2). Similarly, in the 2003 U.S. Food and Drug Administration and U.S. Department of Agriculture, Food Safety and Inspection Service risk assessment, deli meats were implicated as the highest-risk ready-to-eat food vehicles for Listeria monocytogenes (6).

\section{The Listeria bacteria}

Listeria monocytogenes, which is widely referred to as Listeria, is a type of bacterial pathogen that is widely distributed in the environment. It can be found in soil, water, sewage, vegetation and in the feces of humans and animals (7). Due to its psychrotrophic properties, Listeria can survive and multiply on foods stored at refrigerated temperatures (7). Moreover, foods contaminated with the listeria bacteria can look, smell and taste normal (2). The infective dose of $L$. monocytogenes is estimated to be around 10 to 100 million colony forming units (CFU) in healthy hosts, and 0.1 to 10 million CFU in people at high risk of infection (8).

\section{Illness associated with Listeria}

Listeria is responsible for the illness called listeriosis. Listeriosis can be contracted by consumption of food or drink contaminated with the listeria bacteria and during pregnancy from mother to baby (2). Pregnant women, the elderly and the immunocompromised are at higher risk of contracting listeriosis (2). In healthy adults, listeriosis is mainly characterized by enteric symptoms such as vomiting, diarrhea and fever (2). However, in high risk populations an invasive form listeriosis is seen. Invasive listeriosis is characterized by more serious symptoms including meningitis, pneumonia, septicemia, spontaneous abortion, stillbirth and death (2).

\section{Maple Leaf Foods Outbreak}

In 2008, pre-packaged deli meats were the source of a major listeriosis outbreak. Investigations of the Toronto Maple Leaf Foods plant where the meats were produced revealed that the source of the contamination was most likely meat residue which had accumulated deep within the slicing machines of two production lines in the processing plant (9). This residue is believed to have facilitated the growth of listeria 
bacteria which contaminated the deli meats produced on the lines.

\section{Listeria contamination in industrial meat production}

The most important route of food product contamination with Listeria in processing plants is believed to be via contact surfaces.

Contamination of ready-to-eat meat with listeria can be through direct or indirect contact with equipment or people (10). While listeria is usually found in the environment, it is believed to enter food processing facilities through vectors such as humans, equipment, and raw food (10). Once inside a processing facility, the pathogen can adhere to many food contact surface materials including stainless steel and can remain in place for months or years (11). The ability of listeria to adhere and create biofilms on materials is attributed to its presence and persistence in manufacturing facilities (12).

\section{Retail delis more implicated in foodborne} illness cases

In the United States, sliced meats from retail facilities account for approximately $83 \%$ of deli meat listeriosis cases (13). Cross-contamination is likely to play the biggest role in the pathogenic contamination of sliced meats in the retail deli environment (6). Some common practices which have been linked to introduction of contamination into the deli are improper hand washing and glove wearing, contact between ready-to-eat foods and contaminated equipment and improper cleaning and sanitizing (14).

\section{Meat slicer cross-contamination}

Commercial deli slicers are commonly used to slice meats, cheeses, and produce in grocery stores, delis, restaurants, and other foodservice establishments. Meat slicers have been implicated as a major source of listeriosis outbreaks. Studies have shown that meat slicers in food establishments are the primary source of listeria cross-contamination for deli meats (3). Cross-contamination during slicing and subsequent bacterial growth during storage is identified as the main causes of illness caused by consumption of ready-to-eat meats (15).

Depending on microbial load found on the slicer, pathogens are believed to transfer to meats when they come in contact with the slicers during processing (15).

\section{Harbourage of bacteria in meat slicers} Deli meat slicers have been shown to harbor listeria in many parts of the apparatus (16). On a typical deli slicer, many seams between the connected parts and components are sealed with sealants and gaskets. Due to the heavy use and cleaning process that deli slicers are subjected to, the seams can become worn, degraded, or removed (16). As these seals and gaskets become degraded, spaces can be created that can trap moisture and debris contaminated with pathogens (16). Consequently, this allows microorganisms to colonize and form sanitizer resistant biofilms in these areas (16). Once established, these biofilms can release pathogens to meats. One potential way of this occurring is when water drips through these spaces during cleaning, carrying pathogens to the slicer surface which then comes in contact with meat (17). Furthermore, due to spatial constraints, these areas may not be able to be adequately cleaned and sanitized under normal cleaning procedures (16). Examples of meat slicer parts that are inaccessible under normal cleaning include the ring guard mount, the blade guard and the slicer handle (16). Other barriers to proper cleaning of the equipment which contribute to microbial growth on the meat slicers include lack of employee training in following proper cleaning protocols or using incorrect sanitizers (18).

\section{Prevention of contamination}

Decreasing contamination of sliced meats in food establishments may help to reduce incidence of listeriosis and outbreaks (6). Evidence shows that routine, proper cleaning and sanitizing procedures of slicers will likely reduce the risk of foodborne illness caused by cross-contamination during slicing (19). The Canada Food Retail and Food Services Code recommends that in order to maintain adequate sanitation, equipment such as meat slicers should be cleaned every 4 hours with procedures that address the complex design of the equipment (20). According to educational documents published by local health authorities in British Columbia, operators should clean their 
meat slicers in compliance with manufacturer's instructions, with written sanitation procedures posted near the equipment. They also recommend that scheduled service of meat slicers include disassembly of components and replacement of seals and gaskets (25). Moreover, while physical cleaning and sanitation of meat slicers is important in mitigating the risk of cross-contamination, employee knowledge and training has also been documented to be a factor. Proper training of employees with written and visual demonstrations on the operation and cleaning of meat slicers have been shown to be most effective in achieving sanitation standards that prevent the transmission of foodborne illness (18).

\section{Lack of compliance}

Despite the educational efforts of health agencies to prevent the risk of foodborne illness from meat slicers, research suggests that many operators are not following the recommendations. The U.S. Center for Disease Control has reported that retail delis are often out of compliance when it comes to adequate cleaning and sanitation of meat slicers (21). A study that investigated the cleaning frequencies of delis across the US revealed that of the 298 delis that were surveyed, approximately half of them did not fully clean their slicers according to the US Food and Drug Administration's recommendation of every four hours (21). Independent and smaller delis were reported to have lower frequencies of slicer cleaning compared to larger chain delis.

\section{Barriers to compliance}

Retail delis are high traffic areas serving many customers in a short amount of time. Employees of these establishments are expected to work constantly with a sense of urgency (22). In a study which surveyed workers in food establishments, time constraints, inadequate training, forgetting, lack of adequate resources, careless management and inconvenience were identified as barriers to maintaining clean work surfaces (22). Furthermore, owners and managers have implicated factors such as lack of money, time, lack of experience, limited access to information, lack of support, lack of interest and lack of knowledge in affecting food safety compliance in small and medium sizedbusinesses (23).

\section{Role of the EHO}

Under the Food Premises Regulation of British Columbia, operators are required to maintain their equipment in a sanitary condition and clean their equipment according to procedures written in their sanitation plan (24). In British Columbia, Environmental Health Officers are responsible for ensuring that operators are in compliance with these requirements. During inspection of food establishments such as delis, EHOs should pay special attention to meat slicers, making sure they are in a condition that prevents the risk of pathogenic contamination. Furthermore, when reviewing or approving sanitation plans for establishments, EHOs should ensure that cleaning procedures of meat slicers are consistent with those in the Food Code and any policy that may be in place at their local health authority.

\section{Strengths and weaknesses of the literature review}

Several sources that were reviewed implicated meat slicers as the primary source of Listeria contamination of ready-to-eat meats from retail delis. However, all of these sources originated outside Canada and are subject to regional differences. In addition, the CDC study which suggests that many retail delis are not in compliance with recommended meat slicer cleaning procedures was also conducted outside Canada. Variances in ready-to-eat meat consumption, as well as differences food safety legislation and its implementation can influence how meat slicers are operated and sanitized across regions and therefore the generalizability of these sources may be limited.

\section{Gaps in research, policy and knowledge} While it is widely documented that flaws in the design of meat slicers facilitate contamination of food during operation, research on safe designs and the most effective way of sanitation of the equipment which reduces the risk of pathogen harbourage and transmission is lacking. Furthermore, research on knowledge concerning the cleaning and sanitation of ready-to-eat meat 
slicers among the food establishment operators is also limited. Methods and Materials

\section{Research Methodology}

\section{Methods}

An in-person, self-administered paper survey was conducted in this study. The administrator traveled to the selected delis during normal hours of operation and contacted a staff member of the facility such as the store manager. Subsequently, a script, which included information on the reason for conducting this study, was read to the person and a consent form was handed to the staff member to gain their permission for participating in the study. If the person agreed to participate in the study, the participant was handed a paper survey along with a cover letter explaining the purpose of the study and relevant background information.

\section{Materials}

For the purpose of this study, the following materials were used: a computer with internet access, Microsoft Word, NCSS statistical analysis software, and Microsoft Excel. To locate prospective food establishments to be surveyed, Google Earth map software was used. Using this application, delis and supermarkets in the Metro Vancouver region were located and a random list to be surveyed was generated.

\section{Inclusion and Exclusion Criteria}

Any delis and supermarkets in the Metro Vancouver region that utilized at least one meat slicer at their facility were part of the inclusion criteria. Furthermore, any delis or supermarkets in the Metro Vancouver region that did not use a meat slicer were part of the exclusion criteria. Furthermore, delis and supermarkets outside of the Metro Vancouver region were excluded. Finally, any delis and supermarkets within the Metro Vancouver region that were under management of operators who did not speak English were also excluded.

\section{Survey}

The survey comprised of close-ended questions with binary and multichotomous answer options. The survey questions were both nominal and ordinal. Classification questions were asked to categorize the establishment in terms of size.
One section of the survey questioned the establishments on the procedures used for the cleaning and maintenance of their meat slicers. Furthermore, another section of the survey consisted of general food safety knowledge questions.

\section{Results}

\section{Description of Data}

The data collected in this study was a combination of binary and multichotomous nominal data, ordinal data and numerical data. Establishments were classified as being either large or small in size using an ordinal scale. Large establishments were characterized as having 11 or more employees and small establishments as having 10 or fewer. Consequently, survey response data was divided based on the size of the establishment and analyzed separately and then compared for statistical differences and associations between the two categories. Furthermore, numerical data was generated from the procedural portion of the survey. Establishments were assigned a numerical score based on their compliance with the procedures recommended by health authorities. For example, an establishment was assigned a score of 1 for every cleaning and maintenance procedure that they followed which was in compliance with one of the eight recommended. In addition, nominal data was generated from the surveyed establishment for the following parameters concerning meat slicers:

- Maintenance practices

- Methods and frequency of cleaning

- Cultural practices such as posted cleaning instructions

- Operator's knowledge of the most common pathogen associated with deli.

\section{Descriptive Statistics}

Numerical data was analyzed for mean, median, mode, range and standard deviations using Microsoft Excel. Similarly, nominal data was also analyzed for proportions, percentages or ratios using Microsoft Excel (25). Summary of the results of this analysis are presented in the figures on the next page. 


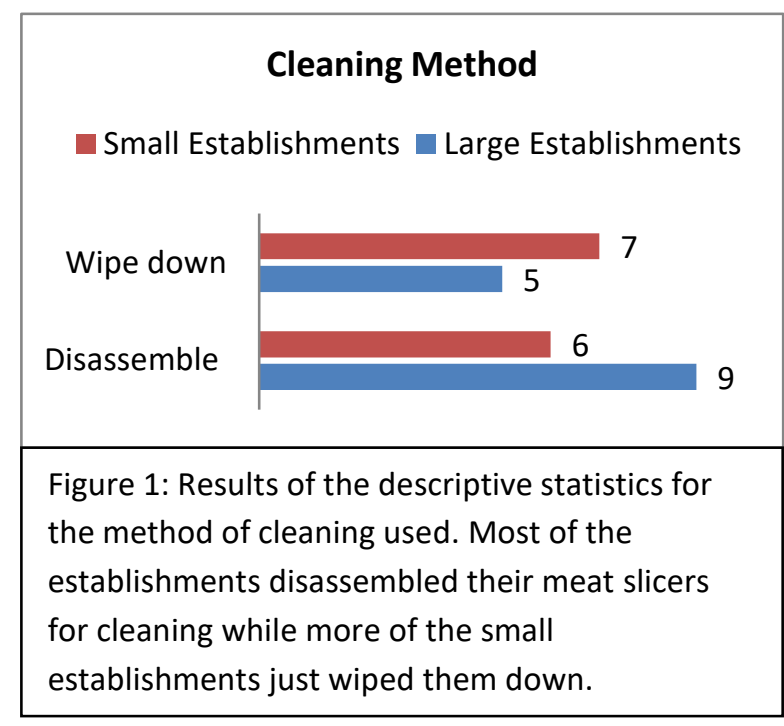

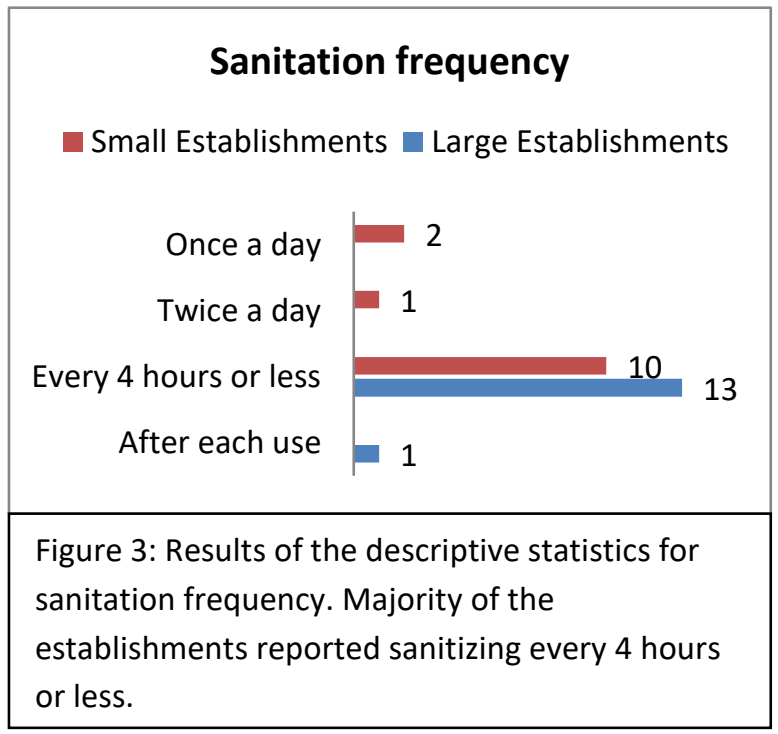

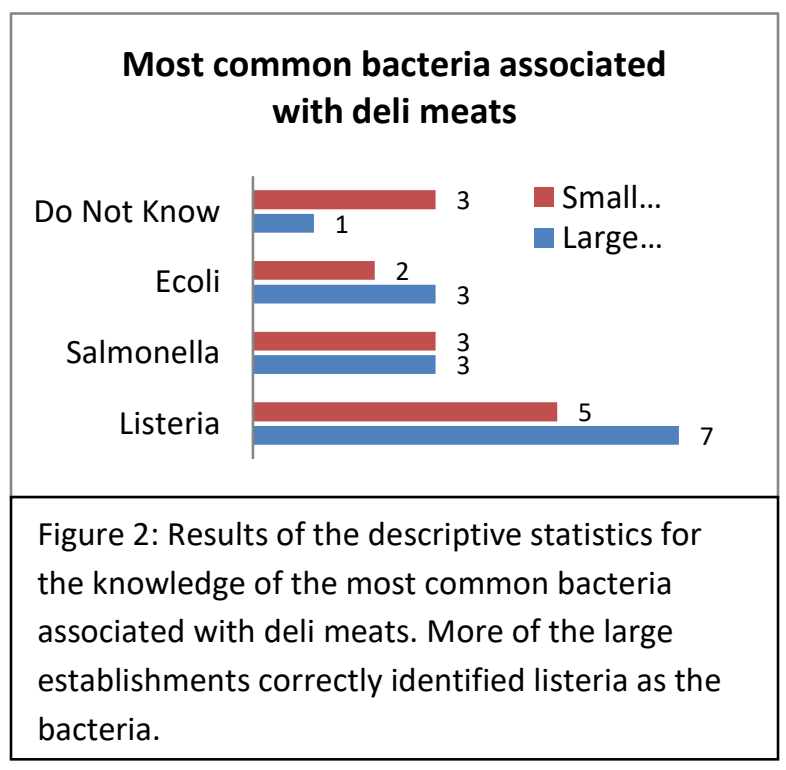

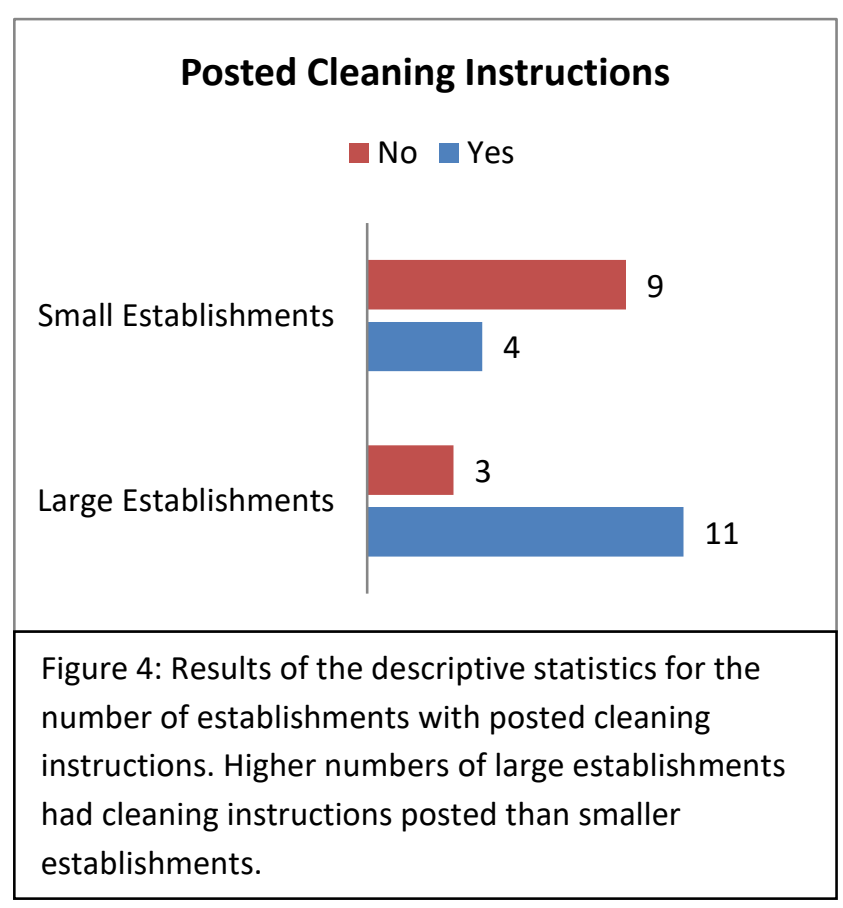

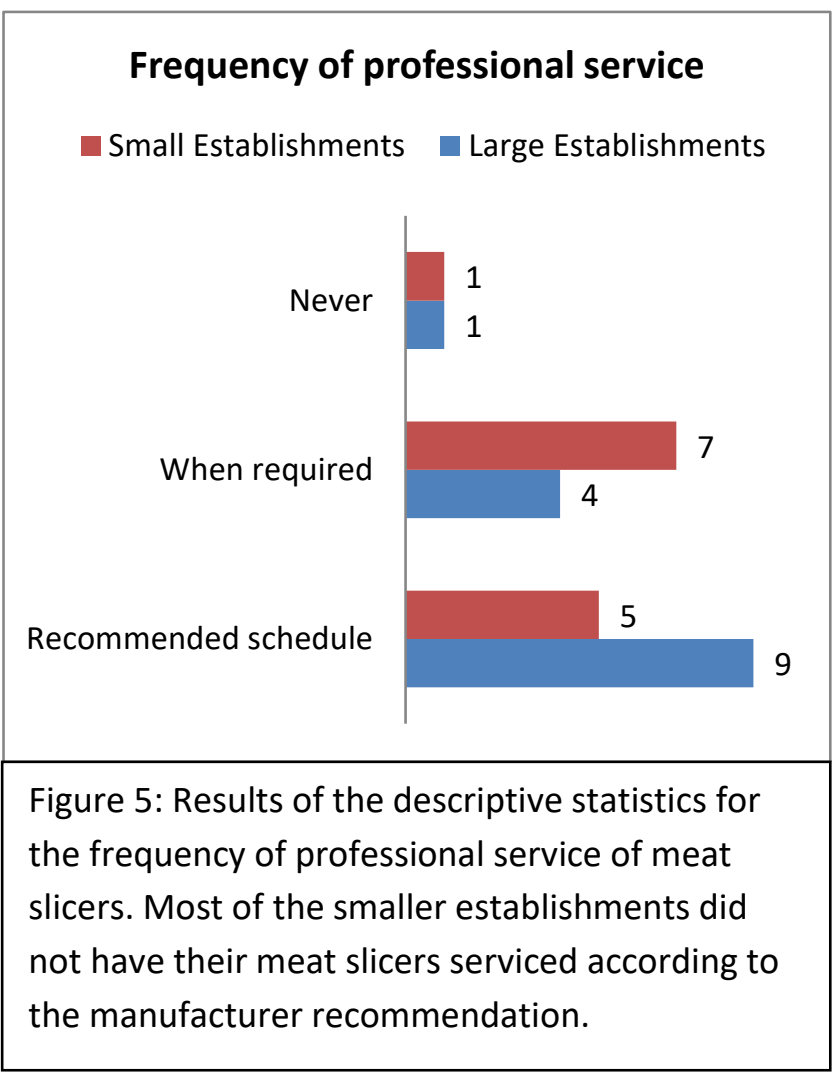




\section{Inferential Statistics}

NCSS, statistics software was used to input data and generate statistical results (26).

To determine if adherence to recommended cleaning procedures by the surveyed establishments was statistically significant in this study, a one-sample t-test was performed. For each correct step that the delis performed, a score was assigned to them. The mean score for the number of correct steps employed by each category of establishments was compared to the 8 steps recommended. Based on the results under Tests of Assumption, the data from establishments was not normally distributed and the non-parametric, Wilcoxon Signed-Rank Test results were analyzed. The statistical analysis indicated a p-value of 0.000003 when $\alpha$ was equal to 0.050 . Therefore, the null hypothesis was rejected, indicating a statistically significant difference between the cleaning procedures performed by the establishments and those recommended. The sampled establishments are not in compliance with all the procedures recommended by health authorities to prevent listeria transmission from meat slicers. The power for this test was 1.00000 or $100 \%$.

Similarly, a two-tailed t-test was performed to determine if there was a difference in the mean score for compliance to the recommendations and the size of the delis. The Tests of Assumptions indicated that the data was normally distributed. Because both categories of the establishments did not have equal variances, the Aspin-Welch Unequal Variance Test results were analyzed and a p-value of 0.00358 was determined. At the significance level of $5 \%$, the null hypothesis was rejected, and it was concluded that there is a statistically significant difference between the size of the establishment and the number of recommended procedures followed. Large establishments showed higher compliance than small delis. The power for this test was determined to be $89 \%$ at a significance level of $5 \%$.

Furthermore, a Chi-square test was also used to determine if an association exists between the size of the establishment, and compliance to the practices recommended to prevent listeria transmission through meat slicers. Upon analysis of the descriptive statistics, those survey questions which revealed major differences in responses between the two categories of establishments were further analyzed using a Chi-square test.

\section{Discussion}

The purpose of this study was to evaluate the cleaning procedures of meat slicers at retail delis in Metro Vancouver. A survey was conducted to determine whether the cleaning procedures practiced at the delis were consistent with those recommended in the Canadian Food Retail and Food Services Code and those published by local health authorities (27). Furthermore, survey results were analyzed to determine if there was an association between the size of the delis and compliance to the recommended procedures. The survey results revealed that delis in Metro Vancouver are not practicing all the cleaning procedures that are recommended. On average, delis only followed six of the eight procedures that have been recommended in the guidance document published by local health authorities (27). Areas where compliance was lacking include frequency of professional service of meat slicers, posting of cleaning instructions and disassembly of the slicer for cleaning.

A statistically significant association between compliance to the number of the recommended cleaning procedures and the size of the delis was generated. Larger delis, with 11 or more employees complied to more procedures than smaller delis with 10 or less employees. These findings are consistent with those published in a study by the United States Center for Disease Control, affirming that small delis have lower compliance rate to the recommended cleaning procedures than large ones (28). However, unlike the CDC results, this study found that almost all of the establishments sanitized their meat slicers every 4 hours or less as recommended in the Food Retail and Food Services Code.

The majority of delis surveyed reported cleaning their meat slicers in compliance to their manufacturer's instructions. However, the 
survey results indicate that while most of the large delis disassembled their meats slicers for cleaning, the majority of small delis just wiped them down. Meat slicers must be disassembled for cleaning in order to reach inaccessible areas that are likely to harbour pathogens such as Listeria monocytogenes (29). Similarly, while all the delis surveyed indicated having a sanitation plan, large delis were more likely to have the cleaning instructions for their meat slicers posted. Having the cleaning instructions posted in a conspicuous location, as reported in the majority of large delis, may explain why large delis were also more likely to disassemble their meat slicer for cleaning. Disassembly of meat slicers is an essential component of the cleaning procedures and stated in virtually all manufacturer instruction manuals (29).

Furthermore, readily available written and visual demonstrations on the cleaning of meat slicers have been linked to achieving sanitation standards that can prevent harbourage of pathogens on meat slicers (18).

The United States Food and Drug Administration along with local health authorities assert that operators should have their meat slicers professionally serviced according to their manufacturers' recommended schedule (29). Timely professional service of meat slicers ensures that meat slicers are maintained in a condition that does not facilitate in pathogen transmission (28). In this study, most of the small establishments did not have their meat slicer serviced according to the manufacturer schedule. Instead, most of the small delis reported having their meat slicers professionally serviced when needed.

All the deli operators surveyed were knowledgeable on the temperature requirements for storing of potentially hazardous food. The operators were also knowledgeable on the frequency of sanitation required for equipment that is used continuously at room temperature for the handling of potentially hazardous foods. However, most of the establishments surveyed were not able to correctly identify Listeria monocytogenes as the most common pathogen associated with deli meats. Most of the establishments that correctly identified the bacteria were characterized as large delis.

\section{Limitations}

A major limitation of this study is the small sample size. An in-person, self-administered survey was chosen for this study. Due to the limited amount time allotted for data collection, only 30 establishments were selected to complete to the survey. Of the 30 establishments selected, only 27 agreed to respond to the survey. Because of the small sample size of 27 delis, the generalizability of this study may be limited. The results derived from the 27 delis surveyed may not be representative of all the delis in Metro Vancouver. Moreover, due to a limited budget and lack of access to a personal vehicle, only those delis that were easily accessible by public transit were selected for the study. This further affected the randomness of the study, and how well the sampled establishments accurately represented the target population.

Furthermore, this study may have also been subjected to response bias. Response bias can occur when a respondent answers survey questions untruthfully or misleadingly (30). The survey questions were comprised of close-ended questions with multiple choice answers.

Selection of certain responses for some of the survey questions would have indicated that the operators were carrying out procedures that were not in compliance with the legislated requirements. Due to social desirability, a type or response bias where a person wants to present themselves in a positive light, some respondents may have been reluctant to choose an answer that would have revealed that they were not following the correct cleaning procedures (30). Consequently, the responses for some questions may have been biased toward what the operators believed was the expected answer and therefore not representative of their actual cleaning procedures.

This study could have been improved by using a different methodology for data collection. Phone interviews could have been conducted instead of in-person, multiple-choice, paper surveys. Phone interviews comprising of open-ended questions 
would have allowed for the operators to describe the cleaning procedures that they practiced in their own words. This method of data collection may have minimized response bias and would have yielded more accurate results. Furthermore, a random sample of delis to be surveyed should have been generated, independent of proximity to public transit. This would have allowed for a more random sample for the study.

\section{Knowledge Translation}

Based on the results of this study, it is evident that not all retail delis in Metro Vancouver are in compliance with the proper sanitation standards for meat slicers. Local health authorities have a duty to ensure that operators are following all the cleaning procedures recommended to prevent contamination of deli meats from meat slicers. One way this can come into practice is through development of inspection guidelines for EHOs that help to verify that deli slicers are being cleaned and maintained properly. Furthermore, in this study most of the operators were unable to identify the most common pathogen associated with deli meats.

Consequently, operators need to be made aware of the common risks associated with handling and consumption of deli meats. Efforts should be made by local health authorities to disseminate educational pamphlets regarding deli meats and sanitation of meat slicers, especially to smaller delis in Metro Vancouver.

\section{Future Research}

This research study focused on evaluating cleaning procedures of meat slicers in retail delis. Adequate cleaning procedures are necessary to prevent contamination of deli meats with pathogens such as Listeria monocytogenes. Based on this research project, the following research opportunities are recommended:

- A study testing for presence of Listeria monocytogenes on deli meats from retail delis in Metro Vancouver. Are deli meats from food establishments in Metro Vancouver safe to eat?

- A study testing for presence of Listeria monocytogenes on meat slicers used in retail delis in Metro Vancouver. Are the cleaning procedures practiced by retail delis adequate to eliminate listeria from meat slicers?

- Survey of high risk populations such as pregnant women on knowledge of Listeria monocytogenes and the risk associated with consumption of deli meats. Is more public awareness needed about the potential risks of ready-to-eat meats?

- Survey of the public about their knowledge of the Maple Leaf listeria outbreak and consumption of deli meats. Has there been a reduction in consumption of deli meats since the news of the outbreak?

\section{Conclusion}

Listeria monocytogenes, a bacterium closely associated with deli meats has been the cause of major foodborne illness outbreaks (1).

Inadequate cleaning of meat slicers have been implicated in transmission of the listeria bacteria with deli meats (15). The results of this study reveal that delis in Metro Vancouver are not in compliance with all of the cleaning procedures of meat slicers recommended to mitigate the risk of pathogen transmission. A statistically significant association was found between the size of a deli and the compliance to recommended sanitation standards. Small delis were found to be less in compliance than large delis. Consequently, the lack of compliance to the recommended cleaning procedures, as revealed through this study, may lead to future outbreaks if timely interventions are not made by local health authorities. 


\section{References}

1. Yearly food-borne illness estimates for Canada [Internet]. Healthycanadians.gc.ca. 2016 [cited 25 October 2016]. Available from: http://healthycanadians.gc.ca/eating-nutrition/risks-recalls-rappelsrisques/surveillance/illness-estimates-estimations-maladies/yearly-annuel-eng.php

2. Listeriosis (Listeria) [Internet]. Phac-aspc.gc.ca. 2016 [cited 25 October 2016]. Available from: http://www.phac-aspc.gc.ca/fs-sa/fs-fi/listerios-eng.php

3. Pouillot R, Gallagher D, Tang J, Hoelzer K, Kause J, Dennis S. $<$ I $>$ Listeria $</ \mathrm{I}>$ $<$ I $>$ monocytogenes $</$ I $>$ in Retail Delicatessens: An Interagency Risk Assessment-Model and Baseline Results. j food prot. 2015;78(1):134-145.

4. Hui Y. Meat science and applications. New York: Marcel Dekker; 2001.

5. Government of Alberta A. Consumer Corner - Eating Patterns in Canada -- Part 2 [Internet]. Www1.agric.gov.ab.ca. 2016 [cited 25 October 2016]. Available from: http://www1.agric.gov.ab.ca/\$department/deptdocs.nsf/all/sis13383

6. Quantitative Assessment of Relative Risk to Public Health from Foodborne Listeria monocytogenes Among Selected Categories of Ready-to-Eat Foods [Internet]. Fda.gov. 2016 [cited 25 October 2016]. Available from: http://www.fda.gov/Food/FoodScienceResearch/RiskSafetyAssessment/ucm1 83966.htm

7. Ray Bhunia A. Fundamental food microbiology.

8. Listeria monocytogenes - Pathogen Safety Data Sheets - Public Health Agency of Canada [Internet]. Phac-aspc.gc.ca. 2012 [cited 25 October 2016]. Available from: http://www.phac-aspc.gc.ca/lab$\mathrm{bio} / \mathrm{res} / \mathrm{psds}-\mathrm{ftss} /$ listeria-monocytogenes-eng.php

9. Weatherill S. Report of the Independent Investigator into the 2008 listeriosis outbreak [Internet]. 1st ed. Ottawa: Agriculture and Agri-Food Canada.; 2009 [cited 25 October 2016]. Available from: http://www.cpha.ca/uploads/history/achievements/09-lirs-rpt_e.pdf

10. Controlling Listeria Contamination in Your Meat Processing Plant [Internet]. Omafra.gov.on.ca. 2016 [cited 25 October 2016]. Available from:

http://www.omafra.gov.on.ca/english/food/inspection/meatinsp/controllinglisteria.htm

11. Kushwaha KMuriana P. Adherence characteristics of Listeria strains isolated from three ready-to-eat meat processing plants. Journal of Food Protection. 2016;72(10):2125-31.

12. Beresford M, Andrew P, Shama G. Listeria monocytogenes adheres to many materials found in foodprocessing environments. Journal of Applied Microbiology. 2001;90(6):1000-1005.

13. [Internet]. Meatinstitute.org. 2016 [cited 25 October 2016]. Available from: https://www.meatinstitute.org/index.php?ht=a/GetDocumentAction/i/59070

14. Control of Listeria monocytogenes in Retail Establishments [Internet]. Extension.psu.edu. 2016 [cited 25 October 2016]. Available from: http://extension.psu.edu/publications/uk137

15. CM L. Cross-contamination between processing equipment and deli meats by Listeria monocytogenes. Journal of Food Protection. 2006;69(1):71-79.

16. Hui Y. Plant sanitation for food processing and food service.

17. Broken Seals, Black Slime, Stowaway Bacteria: The Flaw in Many Deli Slicers | Food Safety News [Internet]. Food Safety News. 2014 [cited 25 October 2016]. Available from: 
http://www.foodsafetynews.com/2014/06/broken-seals-black-slime-stowaway-bacteria-the-flaw-inmany-deli-slicers/\#.WA2IRPkrLrc

18. Neal J. Comparative analysis of training delivery methods for new employees cleaning and sanitizing retail deli slicers: An exploratory study. Food Control. 2013;29(1):149-155.

19. Hoelzer K, Pouillot R, Gallagher D, Silverman M, Kause J, Dennis S. Estimation of Listeria monocytogenes transfer coefficients and efficacy of bacterial removal through cleaning and sanitation. International Journal of Food Microbiology. 2012;157(2):267-277.

20. Food Retail and Food Services Code [Internet]. 1st ed. Canadian Food Inspection System Implementation Group; 2004 [cited 25 October 2016]. Available from: http://foodsafe.ca/resources/Food_Services_Code2004.pdf

21. Brown L, Hoover E, Ripley D, Matis B, Nicholas D, Hedeen N et al. Retail Deli Slicer Cleaning Frequency - Six Selected Sites, United States, 2012. MMWR Morbidity and Mortality Weekly Report. 2016;65(12):306-310.

22. Howells A, Roberts K, Shanklin C, Pilling V, Brannon L, Barrett E. Restaurant Employees' Perceptions of Barriers to Three Food Safety Practices. Journal of the American Dietetic Association. 2007;107(8):A73.

23. Yapp CFairman R. Assessing compliance with food safety legislation in small businesses. British Food Journal. 2005;107(3):150-161.

24. Food Premises Regulation [Internet]. Bclaws.ca. 2016 [cited 25 October 2016]. Available from: http://www.bclaws.ca/EPLibraries/bclaws_new/document/ID/freeside/11_210 99

25. Microsoft Excel. Microsoft; 2010.

26. NCSS Statistical Software. Kaysville, Utah: NCSS; 2017.

27. Food Safety Update [Internet]. 1st ed. Vancouver: Fraser Health and Vancouver Coastal Health; 2013 [cited 25 October 2016]. Available from: https://www.vch.ca/media/Food-Safety-Update-2013.pdf

28. "How Often Retail Delis Clean Their Slicers | EHS-Net | EHS | CDC". Cdc.gov. ～N.p., 2016. Web. 20 Mar. 2017.

29. "Keep Commercial Deli Slicers Safe". Fda.gov. N.p., 2015. Web. 20 Mar. 2017.

30._Lake D. Basics of Research for the Health Professions [Internet]. Pt.armstrong.edu. 2012 [cited 20 March 2017]. Available from: http://www.pt.armstrong.edu/wright/hlpr/text/4.extval.htm 